Research Paper

\title{
Using high-sensitivity sequencing for the detection of mutations in BTK and PLCY2 genes in cellular and cell-free DNA and correlation with progression in patients treated with BTK inhibitors
}

\author{
Adam Albitar ${ }^{1}$, Wanlong Ma ${ }^{1}$, Ivan DeDios ${ }^{1}$, Jeffrey Estella ${ }^{1}$, Inhye Ahn ${ }^{2}$, Mohammed \\ Farooqui ${ }^{3}$, Adrian Wiestner ${ }^{3}$, Maher Albitar ${ }^{1}$ \\ ${ }^{1}$ NeoGenomics Laboratories, Irvine, CA, USA \\ ${ }^{2}$ Medical Oncology Service, National Cancer Institute, Bethesda, MD, USA \\ ${ }^{3}$ Hematology Branch, National Heart, Lung, and Blood Institute, Bethesda, MD, USA
}

Correspondence to: Maher Albitar, email: malbitar@neogenomics.com

Keywords: ibrutinib, CLL, resistance, PLCY2, BTK

Received: August 23, $2016 \quad$ Accepted: January 27, $2017 \quad$ Published: February 13, 2017

\section{ABSTRACT}

Patients with chronic lymphocytic leukemia (CLL) that develop resistance to Bruton tyrosine kinase (BTK) inhibitors are typically positive for mutations in BTK or phospholipase c gamma 2 (PLCY2). We developed a high sensitivity (HS) assay utilizing wild-type blocking polymerase chain reaction achieved via bridged and locked nucleic acids. We used this high sensitivity assay in combination with Sanger sequencing and next generation sequencing (NGS) and tested cellular DNA and cell-free DNA (cfDNA) from patients with CLL treated with the BTK inhibitor, ibrutinib. We also tested ibrutinib-naïve patients with CLL. HS testing achieved 100x greater sensitivity than Sanger. HS Sanger sequencing was capable of detecting $<1$ mutant allele in background of 1000 wild-type alleles (1:1000). Similar sensitivity was achieved with HS NGS. No BTK or PLCY2 mutations were detected in any of the 44 ibrutinib-naïve CLL patients. We demonstrate that without the HS testing $56 \%$ of positive samples would have been missed for BTK and $85 \%$ of PLCY2 would have been missed. With the use of HS, we were able to detect multiple mutant clones in the same sample in $\mathbf{3 7 . 5 \%}$ of patients; most would have been missed without HS testing. We also demonstrate that with HS sequencing, plasma cfDNA is more reliable than cellular DNA in detecting mutations. Our studies indicate that wild-type blocking and HS sequencing is necessary for proper and early detection of BTK or PLCY2 mutations in monitoring patients treated with BTK inhibitors. Furthermore, cfDNA from plasma is very reliable sample-type for testing.

\section{INTRODUCTION}

Bruton tyrosine kinase (BTK) inhibitors like ibrutinib have demonstrated high clinical response rates and durable remissions in patients with chronic lymphocytic leukemia (CLL) including refractory patients to conventional therapy or patients with tumor protein $\mathrm{p} 53$ (TP53) mutations [1-5]. Patients who develop resistance to ibrutinib therapy typically have mutations in either BTK or phospholipase c $\gamma 2$ (PLC $\gamma 2)[1,6]$. Mutations in BTK at the C481S hotspot alter the BTK binding site rendering it reversible to binding ibrutinib which results in a loss of therapeutic activity. Alternatively, mutations in PLC $\gamma 2$, which is immediately downstream of BTK in the B-Cell receptor signaling pathway, result in a gain of function and BTK independent B-Cell Receptor activation [6-8] While the emergence of these mutations has been reported to be associated with resistance to therapy, little is known about the development of these resistance mutations throughout the course of therapy. In clinical trials of CLL patients on BTK inhibitor (BTKi) therapy, whole exome sequencing with next-generation sequencing (NGS) has typically been used to detect specific mutations in BTK or PLC $\gamma 2$ genes $[1,6]$. Therefore, accurate, high-sensitivity assays that can be run in large volumes in a clinical setting are a necessity to further understand the relationship between the appearance of a mutation and the development of resistance to therapy and clinical progression. 
Wild-type blocking polymerase chain reaction (WTB-PCR) followed by Sanger sequencing has demonstrated high sensitivity and versatility in the detection of low frequency mutations $[9,10]$. By adding a short (10-12mer) inaccessible [locked or bridged nucleic acid (LNA or BNA)] oligonucleotide, complementary to wild-type hotspot loci, amplification of the wild-type (WT) allele is inhibited, leading to experimentally driven positive selection for mutant alleles. Because a single nucleotide mismatch in the LNA/BNA-DNA hybrid greatly decreases its melting temperature, only mutant template DNA is free to complete its extension. Therefore, WT DNA is amplified linearly but mutant DNA is amplified exponentially [9]. BNA is a third generation nucleic acid analog with excellent mismatch discriminating power and is considered more potent in blocking. Its strong nuclease resistant properties coupled with a $3^{\prime}$ phosphate also prevents amplification of the wild-type DNA and selectively amplifies mutant DNA $[11,12]$. The resulting WTB-PCR product can then be sequenced by traditional Sanger sequencing methods. We also theorized that the same principle could be applied to NGS library preparation.

While WTB-PCR/Sanger sequencing or WTBPCR/NGS can provide accurate, high-sensitivity mutation analysis, spatial sampling bias in patients with lymphomas or CLL with few circulating tumor cells and lymph node or organ involvement could potentially lead to false negatives [13-18]. This is particularly relevant when tumor heterogeneity is considered. The presence of a mutation in a subclone of the tumor cells can be easily missed if the subclone is not circulating or patchy in bone marrow - if bone marrow aspiration is used. In patients with hematologic diseases, the peripheral blood (PB) plasma has been demonstrated to be enriched for tumor-specific DNA, RNA, and proteins [19-22]. This is especially true for the DNA of the more aggressive subclone. Testing cell-free DNA (cfDNA) from plasma or serum may therefore provide greater sensitivity for detecting resistance mutations than cellular DNA from PB.

In this study we describe the development of highly sensitive Sanger and next-generation sequencing strategies for detecting mutations in BTK and PLC $\gamma 2$ based on WTB-PCR. Using this technology, we demonstrate the development of multiple resistant clones in patients with CLL treated with ibrutinib as they develop resistance to therapy.

\section{RESULTS}

\section{Significant improvement of sensitivity in detecting BTK and PLC $\gamma 2$ mutations using HS assay}

Using the HS assay with WTB-PCR greatly increased sequencing sensitivity when compared to the conventional assay with T-PCR. The conventional assay was able to detect approximately $15-20 \%$ mutant allele in a background of WT allele, while WTB-PCR was able to detect as low as $0.1 \%$ (Figure 1A). Similar sensitivities were obtained for the PLC $\gamma 2$ sequencing, however, some loci were more amenable to positive selection by WTB-PCR than others. Sensitivities for exon 19, 20, and 24 of PLC $\gamma 2$ were $0.2,1$, and $1 \%$, respectively, mutant allele in a background of WT by HS assay (data not shown).

\section{Lack of mutation in BTK and PLC $\gamma 2$ in patients with BTKi-naïve CLL}

Using HS sequencing we tested samples from 44 patients with newly diagnosed CLL or after therapy with FCR. None of these patients showed mutations in BTK exon 15 or PLC $\gamma 2$ Exon 19, 20 and 24 genes.

\section{Mutations in BTK and PLC $\gamma 2$ after BTKi detected by $\mathrm{HS}$}

We tested 63 samples from 16 patients with CLL treated with ibrutinib who were suspected of resistance or who showed evidence of progression while on therapy. Using conventional Sanger sequencing only $21 \%$ of tested samples showed mutations in BTK, while the HS testing showed mutations in $43 \%$ of tested samples $(P<0.00001)$. Mutations in PLC $\gamma 2$ were detected in 5\% of tested samples using conventional Sanger sequencing and in 33\% of samples using HS testing $(P<0.00001)$. The mutations detected included BTK: C481S and C481R; PLC $\gamma 2$ : R665W, L845F, S707Y, P664S, P664L, Ser707TyrdelAlaTyr (6NT deletion). Without HS testing $56 \%$ of positive samples would have been missed for BTK $(N=27)$ and $85 \%$ of PLC $\gamma 2$ $(N=20)$ would have been missed. No mutations detected by the conventional assay were missed by the HS assay.

\section{Multiple subclones with BTK and PLC $\gamma 2$ mutations in BTKi resistant patients detected using HS sequencing}

Overall, of the 16 patients on therapy with ibrutinib and suspected resistance or disease progression, 11 (69\%) had a mutation in either BTK or PLC $\gamma 2,6(37.5 \%)$ patients had mutations in both genes, and 2 (12.5\%) patients had three or more mutations that were detected by HS assay. By comparison, using conventional assay only 6 $(37.5 \%)$ patients had mutations in either BTK or PLC $\gamma 2$, $1(6.3 \%)$ had mutations in both genes, and $1(6.3 \%)$ patient had three or more mutations. More than half of the patients with mutations $(55 \%, N=11)$ had multiple drug resistant mutations that are detectable by the HS assay and two patients had 5 separate mutations (Table 1). The fact that we were able to see three separate subclones (as determined by NGS; Figure 1B) in at least one patient (Patient \# 4) suggests that these other mutations also exist in separate subclones. Without HS testing, $83 \%$ of the additional clones would have been missed. 
Seven of the mutations in PLC $\gamma 2(87.5 \%, N=8)$ and three mutations in BTK $(33 \%, N=9)$ that were detectable by HS assay at progression were undetected by conventional assay. Median percentage of CLL cells in these samples as tested at progression was $58 \%(N=8$, range $=7-93 \%)$ as determined by flow cytometry.

\section{Next-generation sequencing and improvement of sensitivity using blocking oligonucleotides}

In general, resistance mutations in BTK or PLC $\gamma 2$ were detected by NGS in all tested samples, except for two samples: Patient \# 5, who had a very low frequency PLC $\gamma 2$ Exon 20 6NT deletion and patient \# 3, who had two low frequency PLC $\gamma 2$ Exon 19 R665W and Exon 20 S707Y mutations. The addition of BNA/LNA oligonucleotides enriched for BTK and PLC $\gamma 2$ hotspot mutations (Table 2 and Figure 1B). In addition, NGS showed that when multiple mutations were detected in one sample, these mutations were not in tandem and were therefore present in different strands of DNA (Figure 1B). In particular, a sample from patient \# 4, in which three BTK mutations were detected, the three mutations were completely independent events existing in separate DNA strands, thus suggesting different subclones.

\section{Testing using cell-free DNA}

We performed parallel HS sequencing of 9 temporally matched pairs of plasma cfDNA and cellular DNA. Of these 9 pairs, 4 parallel cfDNA isolated from serum were also tested. Of the 9 plasma cfDNA samples, $7(78 \%)$ showed mutations in BTK and $4(44 \%)$ showed mutations in PLC $\gamma 2$. The cellular DNA showed mutations in BTK in $7(78 \%)$ samples, but only $2(22 \%)$ mutations were detected in the PLC $\gamma 2$ gene. Of the 4 serum cfDNA samples, only $1(25 \%)$ showed a mutation in BTK, and 1 $(25 \%)$ had a mutation in PLC $\gamma 2$ (Table 3A).

All mutations detected by either cellular DNA or serum cfDNA were also detected by plasma cfDNA. 2 out of $4(50 \%)$ PLC $\gamma 2$ mutations identified by plasma cfDNA were not detected by cellular DNA in the total 9 paired samples. 2 out of $3(67 \%)$ of both BTK and PLC $\gamma 2$ mutations identified by plasma cfDNA were not detected by serum cfDNA in the total 4 paired samples (Table 3B). It is difficult to quantify the mutation percentage using Sanger or WTB-PCR and sequencing, but overall, mutant peak was relatively significantly stronger in plasma samples as compared with cell samples in almost positive cases.

The number of patients is too small and we cannot determine if plasma positivity correlated with more
A

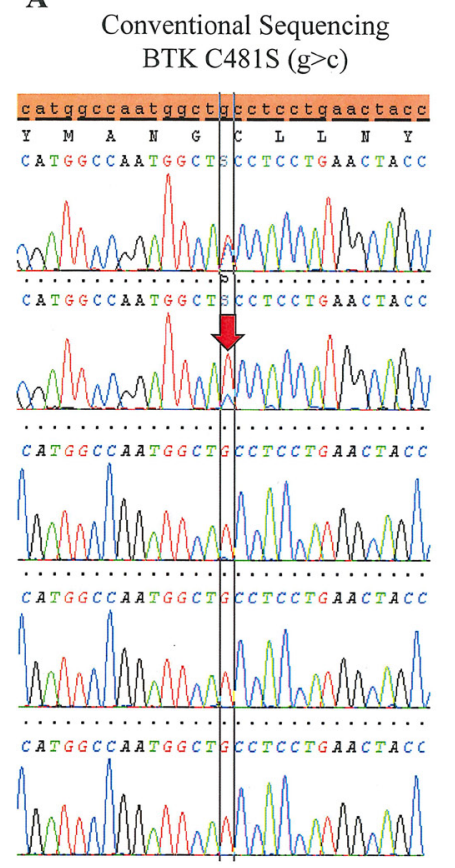

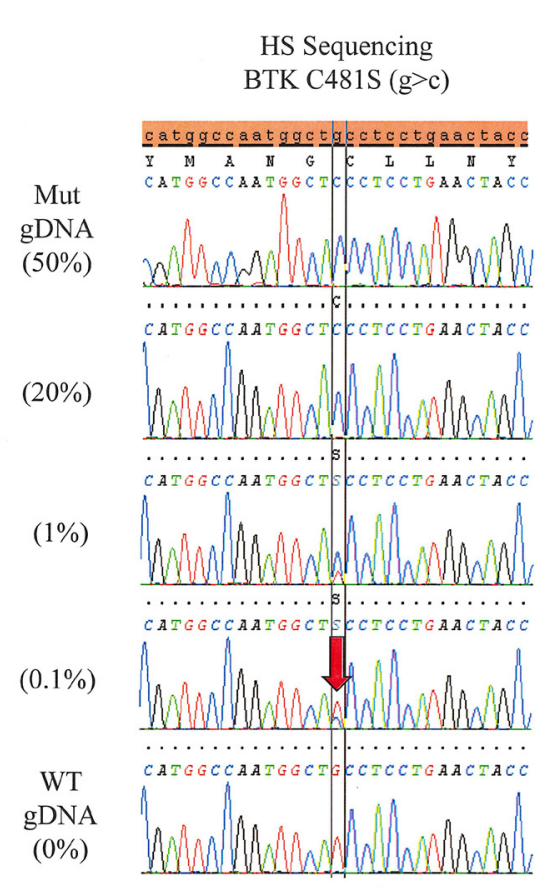

B

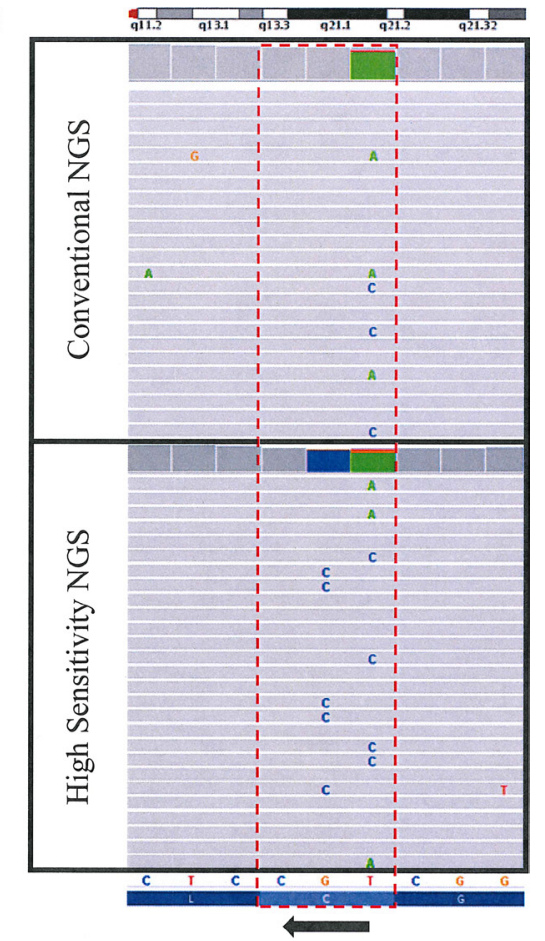

Figure 1: Increase in sensitivity with the addition of BNA/LNA oligonucleotides to sequencing. (A) Sanger Sequencing. Genomic DNA positive for a BTK C481S $(\mathrm{g}>\mathrm{c})$ mutation is serially diluted with WT DNA to determine the limit of detection for the conventional and high-sensitivity (HS) Sanger based assays. Limit of detection is approximately $20 \%$ mutant allele in a background of WT by the conventional assay compared with $0.1 \%$ in the HS assay. (B) Next Generation Sequencing. The lower panel shows the high sensitivity testing of a sample which clearly demonstrates three different DNA strands with three different mutations: $\mathrm{c} .1442 \mathrm{G}>\mathrm{C}$ (C481S), c.1441T $>$ C $(\mathrm{C} 481 \mathrm{R})$ and c.1441T $>$ A $(\mathrm{C} 481 \mathrm{~S})$. The upper panel shows the same sample tested in conventional NGS without the high sensitivity approach. The three mutations were detectable, but at a lower frequency. 
Table 1: Tested patients with suspected clinical progression on ibrutinib therapy
BTK
PLC $\gamma 2$
BTK HS
PLC $\gamma 2$ HS
$\%$ CLL/ WBC

\begin{tabular}{|c|c|c|c|c|c|}
\hline Pat \# 1 & WT & WT & WT & $\begin{array}{l}\text { R665W (c>t) (cells); } \\
\text { P664S (c>t) (plasma) }\end{array}$ & 7.0 \\
\hline Pat \# 2 & WT & WT & WT & $\mathrm{R} 665 \mathrm{~W}(\mathrm{c}>\mathrm{t})$ & 87.8 \\
\hline Pat \# 3 & $\mathrm{C} 481 \mathrm{~S}(\mathrm{~g}>\mathrm{c})$ & WT & $\mathrm{C} 481 \mathrm{~S}(\mathrm{~g}>\mathrm{c})$ & $\begin{array}{c}\text { R665W }(\mathrm{c}>\mathrm{t}) \\
\text { S707Y }(\mathrm{c}>\mathrm{a}) \\
\mathrm{L} 845 \mathrm{~F}(\mathrm{a}>\mathrm{t}, \mathrm{a}>\mathrm{c})\end{array}$ & 61.6 \\
\hline Pat \# 4 & $\mathrm{C} 481 \mathrm{R}(\mathrm{t}>\mathrm{c})$ & $\begin{array}{l}\text { R665W }(\mathrm{c}>\mathrm{t}), \\
\mathrm{L} 845 \mathrm{~F}(\mathrm{a}>\mathrm{t})\end{array}$ & $\begin{array}{c}\mathrm{C} 481 \mathrm{~S}(\mathrm{~g}>\mathrm{c}, \mathrm{t}>\mathrm{a}), \\
\mathrm{C} 481 \mathrm{R}(\mathrm{t}>\mathrm{c})\end{array}$ & $\begin{array}{c}\text { R665W }(\mathrm{c}>\mathrm{t}) \\
\mathrm{L} 845 \mathrm{~F}(\mathrm{a}>\mathrm{t})\end{array}$ & 55.0 \\
\hline Pat \# 5 & $\mathrm{C} 481 \mathrm{~S}(\mathrm{~g}>\mathrm{c})$ & WT & $\mathrm{C} 481 \mathrm{~S}(\mathrm{~g}>\mathrm{c})$ & Ser707TyrdelAlaTyr (6NT deletion) & 48.9 \\
\hline Pat \# 6 & WT & WT & $\mathrm{C} 481 \mathrm{~S}(\mathrm{~g}>\mathrm{c})$ & $\mathrm{R} 665 \mathrm{~W}(\mathrm{c}>\mathrm{t})$ & 21.5 \\
\hline Pat \# 7 & $\mathrm{C} 481 \mathrm{~S}(\mathrm{~g}>\mathrm{c})$ & WT & $\mathrm{C} 481 \mathrm{~S}(\mathrm{~g}>\mathrm{c})$ & $\begin{array}{c}\text { Ser707TyrdelAlaTyr } \\
\text { (6NT deletion) (serum); } \\
\text { S707Y (c }>\text { a) (plasma) }\end{array}$ & 75.0 \\
\hline Pat \# 8 & $\mathrm{C} 481 \mathrm{~S}(\mathrm{~g}>\mathrm{c})$ & WT & $\mathrm{C} 481 \mathrm{~S}(\mathrm{~g}>\mathrm{c})$ & WT & not performed \\
\hline Pat \# 9 & WT & WT & WT & WT & not performed \\
\hline Pat \# 10 & WT & WT & WT & WT & not performed \\
\hline Pat \# 11 & WT & WT & WT & WT & not performed \\
\hline Pat \# 12 & WT & WT & WT & WT & not performed \\
\hline Pat \# 13 & WT & WT & WT & WT & not performed \\
\hline Pat \# 14 & WT & WT & $\mathrm{C} 481 \mathrm{~S}(\mathrm{~g}>\mathrm{c})$ & P664L $(c>t)$ & not performed \\
\hline Pat \# 15 & WT & WT & $\mathrm{C} 481 \mathrm{~S}(\mathrm{~g}>\mathrm{c})$ & WT & not performed \\
\hline Pat \# 16 & $\mathrm{C} 481 \mathrm{~S}(\mathrm{~g}>\mathrm{c})$ & WT & $\mathrm{C} 481 \mathrm{~S}(\mathrm{~g}>\mathrm{c})$ & WT & 92.9 \\
\hline
\end{tabular}

Mutational status of BTK and PLC $\gamma 2$ was determined by conventional and high-sensitivity (HS) Sanger sequencing. "\% CLL/WBC" indicates the percentage of CLL cells of white cell count in the tested samples as determined by flow cytometry. Abbreviation: Pat $=$ Patient, $\mathrm{HS}=$ high-sensitivity, $\mathrm{WBC}=$ white blood cells, $\mathrm{WT}=$ wild-type/unmutated.

enlarged lymph node or lower number of circulating lymphocytes, since most patients with progression also had enlarged lymph nodes. Some of the patients with detectable mutations in cells also had low percentage of circulating CLL cells.

\section{DISCUSSION}

Given the association of BTK and PLC $\gamma 2$ mutations with resistance to ibrutinib therapy, an accurate, highly sensitive assay - capable of being run in large volume - is a necessity. Using WTB-PCR with Sanger sequencing or NGS has multiple advantages in the clinical setting. Increased sensitivities of up to $0.1 \%$ mutant allele in a background of wild-type (Figure 1A) could allow clinicians to detect the presence of resistance mutations early on during the course of therapy. Knowing early on when mutations conferring resistance to therapy emerge and that the majority of the time they co-develop alongside additional sub-clones with resistance mutations (Table 1) may be very helpful in devising a strategy to overcome evolving resistance by, for example, adding additional therapeutic agents.

WTB-PCR/Sanger or WTB-PCR/NGS testing allows broad coverage of mutation hot-spots and the detection of undiscovered mutations; they also provide adequate internal controls for ruling out false positives. Its additional utility in revealing low frequency mutant populations, especially in plasma cfDNA is invaluable and will guide future research.

Because we know the limit of detection for the conventional assay is approximately $15 \%$, mutations that are detectable by HS assay but not by conventional assay are therefore present in only a small fraction of CLL cells at progression despite the relatively high CLL cellularity in the tested samples (Median $=58 \%$ ). The low percentage of CLL with the resistance mutations at time of progression implies that these mutations may have secondary effects on CLL cells lacking BTKi resistance mutations perhaps via tumor microenvironment resulting in loss of therapeutic activity [23-25]. We are analyzing peripheral blood samples and there is a possibility that lymph nodes may contain more significant number of cells with mutation. However, testing lymph nodes might not be a practical approach, especially when these lymph nodes are deep and not easily accessable. Furthermore, the pattern of multiclonal BTK inhibitor resistance is unique, perhaps because of the chronic nature of the disease. In more acute malignancies, clonal evolution is typically 


\section{Table 2: Increased next-generation sequencing sensitivity with the addition of BNA/LNA oligonucleotides}

\begin{tabular}{|c|c|c|c|c|c|c|}
\hline \multirow{2}{*}{\multicolumn{3}{|c|}{ Patient \# 4}} & \multicolumn{2}{|c|}{ High-Sensitivity NGS } & \multicolumn{2}{|c|}{ Conventional NGS } \\
\hline & & & & & & \\
\hline Gene & Nucleotide & Amino Acid & Alternate Variant Frequency & Read Depth & Alternate Variant Frequency & Read Depth \\
\hline PLC $\gamma 2$ & $1993 \mathrm{C}>\mathrm{T}$ & Arg665Trp & 16.6 & 353 & 9.6 & 912 \\
\hline PLC $\gamma 2$ & $2535 \mathrm{~A}>\mathrm{T}$ & Leu845Phe & 62.7 & 126 & 14 & 700 \\
\hline BTK & $1442 \mathrm{G}>\mathrm{C}$ & Cys481Ser & 5 & 309 & 4 & 681 \\
\hline BTK & $1441 \mathrm{~T}>\mathrm{A}$ & Cys481Ser & 6 & 310 & 7 & 680 \\
\hline BTK & $1441 \mathrm{~T}>\mathrm{C}$ & Cys481Arg & 14.9 & 307 & 6 & 680 \\
\hline \multicolumn{7}{|c|}{ Patient \# 16} \\
\hline Gene & Nucleotide & Amino Acid & & & Alternate Variant Frequency & Read Depth \\
\hline BTK & $1442 \mathrm{G}>\mathrm{C}$ & Cys481Ser & & & 51.2 & 697 \\
\hline \multicolumn{7}{|c|}{ Patient \# 5} \\
\hline Gene & Nucleotide & Amino Acid & Alternate Variant Frequency & Read Depth & & \\
\hline BTK & $1442 \mathrm{G}>\mathrm{C}$ & Cys481Ser & 3 & 398 & & \\
\hline \multicolumn{7}{|c|}{ Patient \# 15} \\
\hline Gene & Nucleotide & Amino Acid & Alternate Variant Frequency & Read Depth & & \\
\hline BTK & $1442 \mathrm{G}>\mathrm{C}$ & Cys481Ser & 2 & 89 & & \\
\hline \multicolumn{7}{|c|}{ Patient \# 3} \\
\hline Gene & Nucleotide & Amino Acid & Alternate Variant Frequency & Read Depth & & \\
\hline BTK & $1442 \mathrm{G}>\mathrm{C}$ & Cys481Ser & 73.2 & 102 & & \\
\hline PLC $\gamma 2$ & $2535 \mathrm{~A}>\mathrm{T}$ & Leu845Phe & 3 & 145 & & \\
\hline PLC $\gamma 2$ & $2535 \mathrm{~A}>\mathrm{C}$ & Leu845Phe & 5 & 145 & & \\
\hline
\end{tabular}

All samples used were from patients with suspected progression. High-sensitivity NGS includes BNA/LNA oligonucleotides in library preparation and conventional NGS does not.

linear with one subclone outcompeting the others and giving rise to resistance $[26,27]$. In these cases, however, we observed that 6 of the 16 patients at progression have multiple, persisting subclones (Table 1).

Plasma cfDNA from $\mathrm{PB}$ is more sensitive for detecting resistance mutations than cellular DNA or serum cfDNA (Table 3, Figure 2). While no cellular DNA or serum cfDNA samples with mutant BTK or PLC $\gamma 2$ were wildtype in their respective plasma cfDNA samples, $50 \%$ of the PLC $\gamma 2$ mutations detected in plasma DNA were not detected in their respective cellular DNA samples. Furthermore, $67 \%$ of both BTK and PLC $\gamma 2$ mutations detected in plasma were not detected in serum. Unfortunately no more plasma samples from patients with progression were available for testing. Although more testing of more plasma samples is needed for confirmation, this approach may be very useful in screening patients for resistance mutations, especially in patients with lymphomas or CLL with few circulating tumor cells and lymph node or organ involvement. Because the resistance mutations allow these cells to proliferate despite BTKi therapy, one plausible explanation for this result is that the increased proliferative rate and consequent improper processing of the cellular contents results in plasma enriched with DNA derived from CLL cells possessing resistance mutations. In serum, the coagulation process may unintentionally lyse fragile cells like granulocytes, which has the effect of diluting the serum with non-tumor cfDNA.

In conclusion, our data indicates that incorporating WTB-PCR into Sanger sequencing or NGS is a highly sensitive and invaluable tool in screening and monitoring patients on ibrutinib or other BTKi therapy for resistance mutations. Additionally, plasma from peripheral blood may be more sensitive than serum and even cells in detecting the presence of these resistance mutations. Although the number of cases is small and further confirmation is needed, using these tools we show that multiple low-frequency subclonal populations of CLL with resistance mutations in BTK and PLC $\gamma 2$ are quite common in patients who progress on therapy with ibrutinib. Using this information we can monitor, with increased accuracy, patients on BTKi therapy and make more informed therapy decisions when we detect the presence of mutations known to result in a loss of therapeutic activity. 
Table 3: Cell-free DNA from peripheral blood plasma is more sensitive than serum and cellular DNA A.

\begin{tabular}{|l|l|l|l|}
\hline \multicolumn{2}{c}{ Serum } & 9 & Plasma \\
\hline Samples Tested & 4 & $7(78 \%)$ & 9 \\
\hline BTK Mutation & $1(25 \%)$ & $4(44 \%)$ & $7(78 \%)$ \\
\hline PLC 2 2 Mutation & $1(25 \%)$ & $2(22 \%)$ \\
\hline
\end{tabular}

B.

\begin{tabular}{|l|l|l|l|l|}
\hline \multicolumn{9}{|c}{ BTK } & Tested Samples & Mut \\
\hline & Tested Samples & Mut & Tested & $2 / 4(50 \%)$ \\
\hline Cells/Plasma & $9 / 9$ & $7 / 7(100 \%)$ & $9 / 9$ & $1 / 3(33 \%)$ \\
\hline
\end{tabular}

(A) High-sensitivity testing of 9 temporally matched plasma and cellular samples from the same patients of which 4 serum samples were also available indicates that plasma may be enriched for tumor specific DNA more so than serum and cells. (B) Comparison of mutation status between paired sample-types.

\section{MATERIALS AND METHODS}

\section{Patients and samples}

Samples were collected from ibrutinib-naive CLL patients as well as from patients treated with ibrutinib as a part of the single-arm, phase-2 study of single agent ibrutinib in CLL with and without $17 \mathrm{p}$ deletions conducted at the NIH (NCT01500733). We tested 44 DNA samples from BTK inhibitor naïve patients with CLL by the high-sensitivity (HS) assay for mutations in BTK exon 15 and PLC $\gamma 2$ Exon 19, 20, and 24. This included samples from $\mathrm{PB}$, bone marrow aspirate, and fresh lymph node tissue. We also tested 16 patients with CLL that were on ibrutinib therapy and had suspected resistance or disease progression. The clinical characterstics of these patients is described in details in reference [28]. Briefly, progression was defined as $\geq 50 \%$ increase in sum of the product of

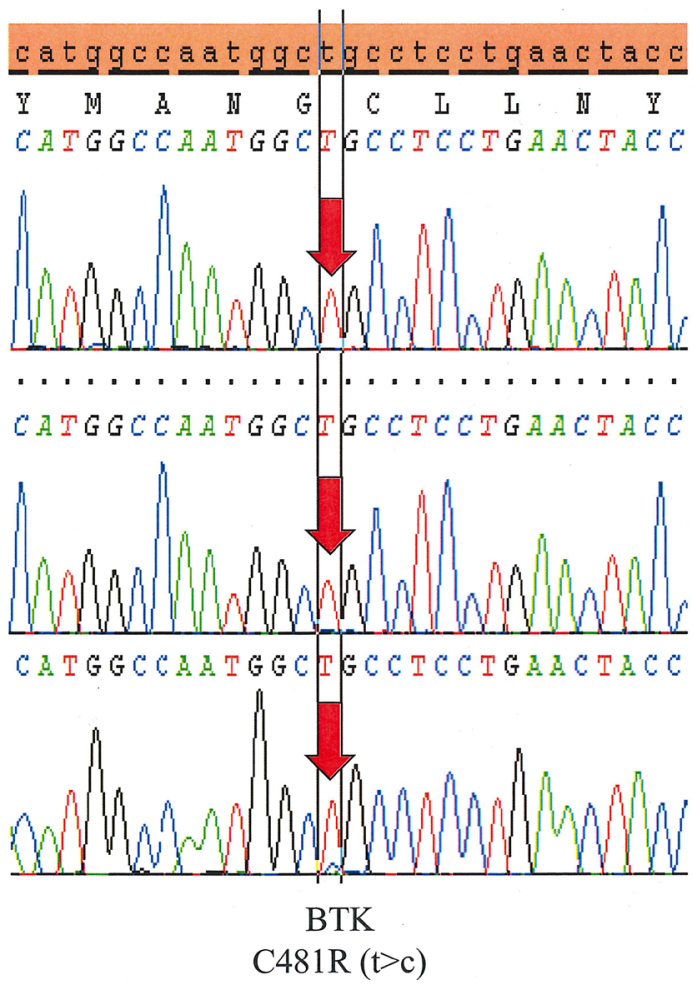

Serum

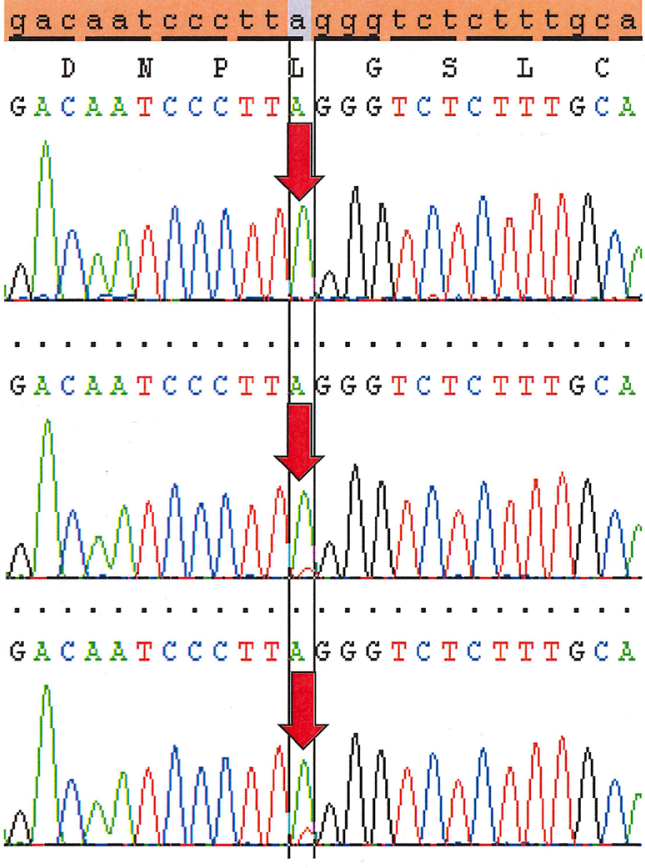

PLCg2 Exon 24

L845F $(a>t)$

Figure 2: Testing DNA derived from peripheral blood plasma is more sensitive than serum and even cells. Temporally matched samples from the same patient (Patient \# 4) reveals both a BTK C481R ( $\mathrm{t}>\mathrm{c})$ and a PLC $\gamma 2$ L845F (a $>\mathrm{t})$ mutation in plasma. The BTK mutation is not detected in cells and both mutations are absent in serum. 
the diameters of representative lymph nodesor $\geq 50 \%$ increase in absolute lymphocyte count, confirmed in two consecutive assessments and with an absolute B-cell count $>5,000 / \mathrm{uL}$ [28]. These duration of ibrutinib therapy in these patients varied between one and three years [28].

Prior treatment data was available for 15 of the 16 patients. Median time from CLL diagnosis until beginning ibrutinib therapy was 5.1 years (range: $0.6-14.9$ ). 3 patients were treatment naïve and 12 were relapsed/refractory (RR) CLL; median number of prior therapies for RR patients was 3.5 (range: 1-6). From these 16 patients we tracked the emergence of resistance mutations in BTK or PLC $\gamma 2$ by both the HS and conventional assay using a total of 63 samples collected over a 43-month period. This also included samples from PB cells $(N=39)$, plasma $(N=10)$, serum $(N=11)$, and bone marrow aspirate $(N=3)$. Samples were either de-identified and tested according to IRBapproved protocol or tested after obtaining a consent form.

From these samples we also performed HS sequencing on 9 temporally matched pairs of plasma cfDNA and cellular DNA. Of these 9 pairs, 4 parallel cfDNA samples isolated from serum were also tested.

DNA extraction: We extracted DNA from PB cells, bone marrow aspirate, and fresh tissue using the QIAamp DNA Mini Kit (Qiagen; Venlo, Netherlands) in both manual and automated (QIAcube) extractions according to manufacturer's instruction. Extracted DNA was then quantified using a Nanodrop 2000 (Thermo Fisher Scientific; Waltham, MA, U.S.A.) instrument and adjusted to approximately $50-100 \mathrm{ng} / \mu \mathrm{L}$ with $\mathrm{H}_{2} \mathrm{O}$.

Total nucleic acid was extracted from PB plasma and serum via the NucliSenS EasyMAG automated platform (BioMerieux; Marcy-l'Étoile, France). DNA was then quantified using Qubit 2.0 Fluorometer (Thermo Fisher Scientific; Waltham, MA, U.S.A.) and adjusted accordingly.

\section{High-sensitivity and conventional sanger DNA sequencing}

The BTK inhibitor resistance assays were developed to amplify exon 15 of BTK and exon 19, 20 and 24 of PLC $\gamma 2$. 0.25 $\mu$ L FastStart Taq DNA Polymerase, $5 \mathrm{U} / \mu \mathrm{l}$ in storage and dilution buffer Fast Start Taq DNA polymerase (Roche; Basel, Switzerland), $2.5 \mu \mathrm{L}$ PCR reaction buffer $10 \times \mathrm{w} / 20 \mathrm{mM} \mathrm{MgCl}, 250 \mu \mathrm{M}$ dNTPs (Invitrogen; Waltham, MA, U.S.A.), $0.4 \mu \mathrm{M}$ forward primer, $0.4 \mu \mathrm{M}$ reverse primer (IDT; Coralville, IA, U.S.A.) (Table 4), and $2 \mu \mathrm{L}$ genomic DNA (50-100 ng/ $\mu \mathrm{L})$ were added to DNAse, RNAse-free, ultra-pure $\mathrm{H}_{2} \mathrm{O}$ to create a final solution volume of $25 \mu \mathrm{L}$ per reaction. All PCR primers were designed with a 5'-M13 sequence (M13forward: tgt aaa acg acg gcc agt; M13-reverse: cag gaa aca gct atg acc) to allow for annealing of complementary sequencing primers. The HS assays were identical to their conventional counterparts except for the addition of BNA (Bio-Synthesis; Lewisville, TX, U.S.A.) or LNA
(Exiqon; Woburn, MA, U.S.A.) oligonucleotides A3, B3, C3, and D3 (Table 4) being added to the master mixes of BTK and PLC $\gamma 2$ Exon 19, 20, and 24, respectively. A3 was added to the BTK master-mix at $4 \mu \mathrm{M}$; B3 to PLC $\gamma 2$ Exon 19 at $4 \mu \mathrm{M}$; C3 to PLC $\gamma 2$ Exon 20 at $40 \mathrm{nM}$; D3 to PLC $\gamma 2$ Exon 24 at $4 \mu \mathrm{M}$. The LNA oligos were designed to feature a $3^{\prime}$ inverted dT to inhibit both extension by DNA polymerase and degradation by $3^{\prime}$ exonuclease. The BNA oligos were designed with a $3^{\prime}$ phosphate for the same reason. All reactions were subjected to identical thermocycler settings; initial denaturation at $95^{\circ} \mathrm{C}$ for 6 minutes; 40 cycles of denaturation at $95^{\circ} \mathrm{C}$ for 30 seconds, primer annealing at $56^{\circ} \mathrm{C}$ for 30 seconds, and extension at $72^{\circ} \mathrm{C}$ for 1 minute 20 seconds; this was followed by a final extension at $72^{\circ} \mathrm{C}$ for 10 minutes. PCR products were purified using Agencourt AMPure XP magnetic beads (Beckman Coulter; Brea, CA, U.S.A.), bi-directionally sequenced using a BigDye Terminator v3.1 Cycle sequencing kit (Life Technologies; Waltham, MA, U.S.A.), and subjected to ethanol precipitation. The precipitated DNA was then resuspended in $10 \mu \mathrm{L}$ Hi-Di Formamide (Life Technologies; Waltham, MA, U.S.A.), denatured at $95^{\circ} \mathrm{C}$ for 3 minutes, and run on the $\mathrm{ABI}$ 3730XL sequencer. Sequencing data were base-called by sequencing software and analyzed by ABI Prism ${ }^{\circledR}$ SeqScape software.

In order to determine the sensitivity and limit of detection, dilution series experiments with genomic or amplicon DNA were carried out. Genomic DNA taken from samples that tested positive for BTK (C481S) or PLC $\gamma 2$ (R665W) or amplicon DNA with PLC $\gamma 2$ (S707Y, L845F) mutations were quantified using a Qubit dsDNA high-sensitivity assay kit (Invitrogen; Waltham, MA, U.S.A.). This DNA was serially diluted with WT DNA of the same type.

\section{Next-generation DNA sequencing}

We applied the WTB-PCR principle to custom SureSelect QXT Target Enrichment (Agilent; La Jolla, CA) and Nextera Rapid Capture (Illumina; San Diego, CA) panels with the addition of the BNA/LNA oligonucleotides (A3, B3, C3, D3; Table 4) in order to increase our limit of detection for the hotspot mutations in hybrid-capture based NGS. A3, B3, and D3 were added to library preparation at a working concentration of $2 \mu \mathrm{M}$ and $\mathrm{C} 3$ was added at $40 \mathrm{nM}$. Both panels cover 315 genes that include the BTK and PLC $\gamma 2$ genes. One sample that was positive for resistance mutations in BTK and PLC $\gamma 2$ was tested by Nextera Rapid Capture based assay with and without WTB-PCR in order to determine if mutant enrichment could be achieved in the NGS setting. One additional sample with resistance mutations was tested by the same assay without WTB-PCR. The SureSelect QXT Target Enrichment based assay with WTB-PCR was used on 3 additional samples with resistance mutations. 
Table 4: Primers and BNA/LNA oligonucleotides

\begin{tabular}{|c|c|c|}
\hline & Oligo Name & Sequence \\
\hline A1 & BTK-FW & 5'-tgt aaa acg acg gec agt CAG TTG TAT GGC GTC TGC AC-3' \\
\hline A2 & BTK-REV & 5'-cag gaa aca get atg acc TCC AGG TAT TCC ATG GCT TC-3' \\
\hline A3 & BTK-BNA & $5^{\prime}-\mathrm{G}+\mathrm{GA}+\mathrm{G}+\mathrm{G}+\mathrm{C}+\mathrm{A}+\mathrm{G}+\mathrm{C}+\mathrm{CAT}+\mathrm{TG}-[$ Phosphate]-3' \\
\hline B1 & PLC $\gamma 2-$ Exon19-FW & 5'-tgt aaa acg acg gec agt GCT CAC CTG GTC GTT TTC C-3' \\
\hline B2 & PLC $\gamma 2-E x o n 19-R E V$ & 5'-cag gaa aca get atg acc CAA GCC CCT CTG TAG AGC AT-3' \\
\hline B3 & PLC $\gamma 2$-Exon19-LNA & $5^{\prime}-+\mathrm{G}+\mathrm{A}+\mathrm{T}+\mathrm{T}+\mathrm{C}+\mathrm{CC}+\mathrm{C}+\mathrm{G}+\mathrm{G} / 3 \mathrm{InvdT} / \mathbf{3}^{\prime}$ \\
\hline $\mathrm{C} 1$ & PLC $\gamma 2$-Exon20-FW & 5'-tgt aaa acg acg gec agt AAA AAT TGT TTG GCC ACC AG-3' \\
\hline $\mathrm{C} 2$ & PLC $\gamma 2-E x o n 20-R E V$ & 5'-cag gaa aca get atg acc TGG TGA ATA CTC AGA GGT TTG C-3' \\
\hline $\mathrm{C} 3$ & PLC $\gamma 2$-Exon20-BNA & $5^{\prime}-\mathrm{G}+\mathrm{G}+\mathrm{AC}+\mathrm{C}+\mathrm{T}+\mathrm{C}+\mathrm{CG}+\mathrm{C}+\mathrm{CT}-[$ Phosphate $]-3^{\prime}$ \\
\hline D1 & PLC $\gamma 2-E x o n 24-F W$ & 5'-tgt aaa acg acg gcc agt AAA CGG TGT GCT TTG GAA AC-3' \\
\hline D2 & PLC $\gamma 2-E x o n 24-R E V$ & 5'-cag gaa aca get atg acc AGA CAG GAC CCT GTG TCA GC-3' \\
\hline D3 & PLC $\gamma 2$-Exon24-LNA & $5^{\prime}-+\mathrm{C}+\mathrm{T}+\mathrm{T}+\mathrm{A}+\mathrm{G}+\mathrm{G}+\mathrm{G}+\mathrm{T}+\mathrm{C}+\mathrm{TC} / 3 \mathrm{InvdT} / \mathbf{3}^{\prime}$ \\
\hline
\end{tabular}

Abbreviation: $\mathrm{FW}=$ forward, $\mathrm{REV}=$ reverse,$+\mathrm{N}=\mathrm{BNA} / \mathrm{LNA}$ bases.

\section{Abbreviations}

BTK: Bruton tyrosine kinase, PLC $\gamma 2$ : Phospholipase c gamma 2, cfDNA: Cell-free DNA, HS: High sensitivity, NGS: Next generation sequencing, WTB-PCR: Wild-type blocking-polymerase chain reaction

\section{ACKNOWLEDGMENTS}

None.

\section{CONFLICTS OF INTEREST}

Adam Albitar, Wanlong Ma, Ivan DeDios, Jeffrey Estella, and Maher Albitar: Work for a diagnostic company offering testing for BTK and PLC $\gamma 2$. Adrian Wiestner: Receives research funding from PCYC.

\section{GRANT SUPPORT}

IA, MF, and AW are supported by the Intramural Research Program of the NHLBI and NCI.

\section{REFERENCES}

1. Maddocks KJ, Ruppert AS, Lozanski G, Heerema NA, Zhao W, Abruzzo L, Lozanski A, Davis M, Gordon A, Smith LL, Mantel R, Jones JA, Flynn JM, et al. Etiology of ibrutinib therapy discontinuation and outcomes in patients with chronic lymphocytic leukemia. JAMA Oncol. 2015; 1:80-7.

2. Byrd JC, Furman RR, Coutre SE, Flinn IW, Burger JA, Blum KA, Grant B, Sharman JP, Coleman M, Wierda WG, Jones JA, Zhao W, Heerema NA, et al. Targeting BTK with ibrutinib in relapsed chronic lymphocytic leukemia. N Engl J Med. 2013; 369:32-42.
3. Farooqui MZ, Valdez J, Martyr S, Aue G, Saba N, Niemann CU, Herman SE, Tian X, Marti G, Soto S, Hughes TE, Jones J, Lipsky A, et al. Ibrutinib for previously untreated and relapsed or refractory chronic lymphocytic leukaemia with TP53 aberrations: a phase 2, single-arm trial. Lancet Oncol. 2015; 16:169-76.

4. Byrd JC, Furman RR, Coutre SE, Burger JA, Blum KA, Coleman M, Wierda WG, Jones JA, Zhao W, Heerema NA, Johnson AJ, Shaw Y, Bilotti E, Zhou C, et al. Three-year follow-up of treatment-naive and previously treated patients with CLL and SLL receiving single-agent ibrutinib. Blood. 2015; blood-2014.

5. Advani RH, Buggy JJ, Sharman JP, Smith SM, Boyd TE, Grant B, Kolibaba KS, Furman RR, Rodriguez S, Chang BY, Sukbuntherng J, Izumi R, Hamdy A, et al. Bruton tyrosine kinase inhibitor ibrutinib (PCI-32765) has significant activity in patients with relapsed/refractory B-cell malignancies. J Clin Oncol. 2013; 31:88-94.

6. Woyach JA, Furman RR, Liu T-M, Ozer HG, Zapatka M, Ruppert AS, Xue L, Li DH, Steggerda SM, Versele M, Dave SS, Zhang J, Yilmaz AS, et al. Resistance mechanisms for the Bruton's tyrosine kinase inhibitor ibrutinib. N Engl J Med. 2014; 370:2286-94.

7. Woyach JA, Johnson AJ, Byrd JC. The B-cell receptor signaling pathway as a therapeutic target in CLL. Blood. 2012; 120:1175-84.

8. Zhou Q, Lee G-S, Brady J, Datta S, Katan M, Sheikh A Martins MS, Bunney TD, Santich BH, Moir S, Kuhns DB, Long Priel DA, Ombrello A, et al. A hypermorphic missense mutation in PLCG2, encoding phospholipase $\mathrm{C} \gamma 2$, causes a dominantly inherited autoinflammatory disease with immunodeficiency. Am J Hum Genet. 2012; 91:713-20.

9. Dominguez PL, Kolodney MS. Wild-type blocking polymerase chain reaction for detection of single nucleotide minority mutations from clinical specimens. Oncogene. $2005 ; 24: 6830-4$. 
10. Albitar A, Ma W, DeDios I, Estella J, Agersborg S, Albitar M. Positive selection and high sensitivity test for MYD88 mutations using locked nucleic acid. Int J Lab Hematol. 2016; 38:133-40.

11. Abdur Rahman S, Seki S, Utsuki K, Obika S, Miyashita K, Imanishi T. 2', 4'-BNA NC: a novel bridged nucleic acid analogue with excellent hybridizing and nuclease resistance profiles. Nucleosides Nucleotides Nucleic Acids. 2007; 26:1625-8.

12. Abdur Rahman S, Seki S, Obika S, Yoshikawa H, Miyashita K, Imanishi T. Design, synthesis, and properties of 2', 4'-BNANC: a bridged nucleic acid analogue. J Am Chem Soc. 2008; 130:4886-96.

13. Bashashati A, Ha G, Tone A, Ding J, Prentice LM, Roth A, Kalloger S, Senz J, Yang W, McConechy M, Melnyk N, Anglesio M, Luk MT, et al. Distinct evolutionary trajectories of primary high-grade serous ovarian cancers revealed through spatial mutational profiling. J Pathol. 2013;231:21-34.

14. Campbell PJ, Yachida S, Mudie LJ, Stephens PJ, Pleasance ED, Stebbings LA, Morsberger LA, Latimer C, McLaren S, Lin ML, McBride DJ, Varela I, Nik-Zainal SA, et al. The patterns and dynamics of genomic instability in metastatic pancreatic cancer. Nature. 2010; 467:1109-13.

15. Gerlinger M, Rowan AJ, Horswell S, Larkin J, Endesfelder D, Gronroos E, Martinez P, Matthews N, Stewart A, Tarpey P, Varela I, Phillimore B, Begum S, et al. Intratumor heterogeneity and branched evolution revealed by multiregion sequencing. N Engl J Med. 2012; 366:883-92.

16. Gerlinger M, Horswell S, Larkin J, Rowan AJ, Salm MP, Varela I, Fisher R, McGranahan N, Matthews N, Santos CR, Martinez P, Phillimore B, Begum S et al. Genomic architecture and evolution of clear cell renal cell carcinomas defined by multiregion sequencing. Nat Genet. 2014; 46:225-33.

17. Haffner MC, Mosbruger T, Esopi DM, Fedor $\mathrm{H}$, Heaphy CM, Walker DA, Adejola N, Gürel M, Hicks J, Meeker AK, Halushka MK, Simons JW, Isaacs WB, et al. Tracking the clonal origin of lethal prostate cancer. J Clin Invest. 2013; 123:4918-22.

18. Sottoriva A, Spiteri I, Piccirillo SG, Touloumis A, Collins VP, Marioni JC, Curtis C, Watts C, Tavaré S. Intratumor heterogeneity in human glioblastoma reflects cancer evolutionary dynamics. Proc Natl Acad Sci. 2013; 110:4009-14.

19. Manshouri T, Do K, Wang X, Giles FJ, O’Brien SM, Saffer H, Thomas D, Jilani I, Kantarjian HM, Keating MJ,
Albitar M. Circulating CD20 is detectable in the plasma of patients with chronic lymphocytic leukemia and is of prognostic significance. Blood. 2003; 101:2507-13.

20. Rogers A, Joe Y, Manshouri T, Dey A, Jilani I, Giles F, Estey E, Freireich E, Keating M, Kantarjian H, Albitar M. Relative increase in leukemia-specific DNA in peripheral blood plasma from patients with acute myeloid leukemia and myelodysplasia. Blood. 2004; 103:2799-801.

21. Ma W, Tseng R, Gorre M, Jilani I, Keating M, Kantarjian H, Cortes J, O'Brien S, Giles F, Albitar M. Plasma RNA as an alternative to cells for monitoring molecular response in patients with chronic myeloid leukemia. Haematologica. 2007; 92:170-5.

22. Ma W, Kantarjian H, Zhang X, Sun W, Buller AM, Jilani I, Schwartz JG, Giles F, Albitar M. Higher detection rate of JAK2 mutation using plasma. Blood. 2008; 111:3906-7.

23. Ponader S, Chen S-S, Buggy JJ, Balakrishnan K, Gandhi V, Wierda WG, Keating MJ, O'Brien S, Chiorazzi N, Burger JA. The Bruton tyrosine kinase inhibitor PCI-32765 thwarts chronic lymphocytic leukemia cell survival and tissue homing in vitro and in vivo. Blood. 2012; 119:1182-9.

24. Endo T, Nishio M, Enzler T, Cottam HB, Fukuda T, James DF, Karin M, Kipps TJ. BAFF and APRIL support chronic lymphocytic leukemia B-cell survival through activation of the canonical NF- $\kappa$ B pathway. Blood. 2007; 109:703-10.

25. Kern C, Cornuel J-F, Billard C, Tang R, Rouillard D, Stenou V, Defrance T, Ajchenbaum-Cymbalista F, Simonin PY, Feldblum S, Kolb JP. Involvement of BAFF and APRIL in the resistance to apoptosis of B-CLL through an autocrine pathway. Blood. 2004; 103:679-88.

26. Anderson K, Lutz C, Van Delft FW, Bateman CM, Guo Y, Colman SM, Kempski H, Moorman AV, Titley I, Swansbury J, Kearney L, Enver T, Greaves M. Genetic variegation of clonal architecture and propagating cells in leukaemia. Nature. 2011; 469:356-61.

27. Ding L, Ley TJ, Larson DE, Miller CA, Koboldt DC, Welch JS, Ritchey JK, Young MA, Lamprecht T, McLellan MD, McMichael JF, Wallis JW, Lu C, Shen D, et al. Clonal evolution in relapsed acute myeloid leukaemia revealed by whole-genome sequencing. Nature. 2012; 481:506-10.

28. Ahn I, Underbayev C, Albitar A, Herman S, Tian X, Maric I, Arthur DC, Wake L, Pittaluga S, Yuan CM, StetlerStevenson M, Soto S, Valdez J, et al. Clonal Evolution Leading to Ibrutinib Resistance in Chronic Lymphocytic Leukemia. Blood. 2016, In press. 